\title{
Hysteresis Controlled Based Power Quality Improvement in a Renewable Energy Source Connected to Utility grid with BESS Based STATCOM
}

\author{
Ch Vasantha Rao I M. Sivanageswararao ${ }^{2}$ \\ ${ }_{1}^{1}$ PG Scholar, Department of EEE, Priyadarshini Institute of Technology \& Science, Chintalapudi, India. \\ ${ }^{2}$ Assistant Professor, Department of EEE, Priyadarshini Institute of Technology \& Science, Chintalapudi, India.
}

To Cite this Article

Ch Vasantha Rao and M. Sivanageswararao, "Hysteresis Controlled Based Power Quality Improvement in a Renewable Energy Source Connected to Utility grid with BESS Based STATCOM", International Journal for Modern Trends in Science and Technology, Vol. 07, Issue 03, March 2021, pp.: 250-255.

\section{Article Info}

Received on 15-February-2021, Revised on 10-March-2021, Accepted on 21-March-2021, Published on 23-March-2021.

\section{ABSTRACT}

This Paper presents a control strategy of the grid interconnected inverter Renewable Energy Sources (RES). This system can achieve the maximum benefits from these grid interconnected inverter when installed in 3-phase 4-wire distribution system. Increasing electrification of daily life causes growing electricity consumption and the rising number of sensitive or critical loads demand for high quality electricity. One of the main problems facing today is that related with the transmission and distribution of electricity. Due to the rapid increase in global energy consumption and the diminishing of fossil fuels, the customer demand for new generation capacities and efficient energy production, delivery and utilization keeps rising. Utilizing distributed generation, renewable energy and energy storage can potentially solve problems as energy shortage. With the increase in load demand, the Renewable Energy Sources (RES) are increasingly connected in the distribution systems which utilizes power electronic Converters/Inverters.

The inverter can perform as a multi function device by incorporating active power filter functionality. The inverter can thus be utilized as: 1) power converter to inject power generated from RES to the grid, and 2) shunt APF to compensate current unbalance, load current harmonics, load reactive power demand and load neutral current. All of these functions may be accomplished either individually or simultaneously. This new control concept is demonstrated with extensive MATLAB/Simulink simulation studies and validated through digital signal processor-based laboratory experimental results.

KEYWORDS: Photo Voltaic, Active Power filter, RES, Wind Energy, Power Quality

\section{INTRODUCTION}

The increasing number of renewable energy sources and distributed generators requires new strategies for the operation and management of the electricity grid in order to maintain or even to improve the power-supply reliability and quality. In addition, liberalization of the grids leads to new management structures, in which trading of energy and power is becoming increasingly important. The power-electronic technology plays an important role in distributed generation and in integration of renewable energy sources into the electrical grid, and it is widely used and rapidly expanding as these applications become more integrated with the grid-based systems.

During the last few years, power electronics has undergone a fast evolution, which is mainly due to two factors. The first one is the development of fast semiconductor switches that are capable of 
switching quickly and handling high powers. The second factor is the introduction of real-time computer controllers that can implement advanced and complex control algorithms. These factors together have led to the development of cost-effective and grid-friendly converters.

Renewable energy source (RES) integrated at distribution level is termed as distributed generation (DG). The utility is concerned due to the high penetration level of intermittent RES in distribution systems as it may pose a threat to network in terms of stability, voltage regulation and power-quality $(\mathrm{PQ})$ issues. Therefore, the DG systems are required to comply with strict technical and regulatory frameworks to ensure safe, reliable and efficient operation of overall network. With the advancement in power electronics and digital control technology, the DG systems can now be actively controlled to enhance the system operation with improved PQ at PCC. However, the extensive use of power electronics based equipment and non-linear loads at PCC generate harmonic currents, which may deteriorate the quality of power [1], [2].

Generally, current controlled voltage source inverters are used to interface the intermittent RES in distributed system. Recently, a few control strategies for grid connected inverters incorporating PQ solution have been proposed. In [3] an inverter operates as active inductor at a certain frequency to absorb the harmonic current. But the exact calculation of network inductance in real-time is difficult and may deteriorate the control performance. A similar approach in which a shunt active filter acts as active conductance to damp out the harmonics in distribution network is proposed in [4]. In [5], a control strategy for renewable interfacing inverter based on - theory is proposed. In this strategy both load and inverter current sensing is required to compensate the load current harmonics.

The non-linear load current harmonics may result in voltage harmonics and can create a serious PQ problem in the power system network. Active power filters (APF) are extensively used to compensate the load current harmonics and load unbalance at distribution level. This results in an additional hardware cost. However, in this paper authors have incorporated the features of APF in the, conventional inverter interfacing renewable with the grid, without any additional hardware cost. Here, the main idea is the maximum utilization of inverter rating which is most of the time underutilized due to intermittent nature of
RES. It is shown in this paper that the grid-interfacing inverter can effectively be utilized to perform following important functions:

1) Transfer of active power harvested from the renewable resources (wind, solar, etc.).

2) Load reactive power demand support.

3) Current harmonics compensation at PCC and

4) Current unbalance and neutral current compensation in case of 3-phase 4-wire system.

Moreover, with adequate control of grid-interfacing inverter, all the four objectives can be accomplished either individually or simultaneously. The PQ constraints at the PCC can therefore be strictly maintained within the utility standards without additional hardware cost.

The paper is arranged as follows: Section II describes the system under consideration and the controller for grid-interfacing inverter. A digital simulation study is presented in Section III. Extensive experimental results are discussed in Section IV and, finally, Section V concludes the paper.

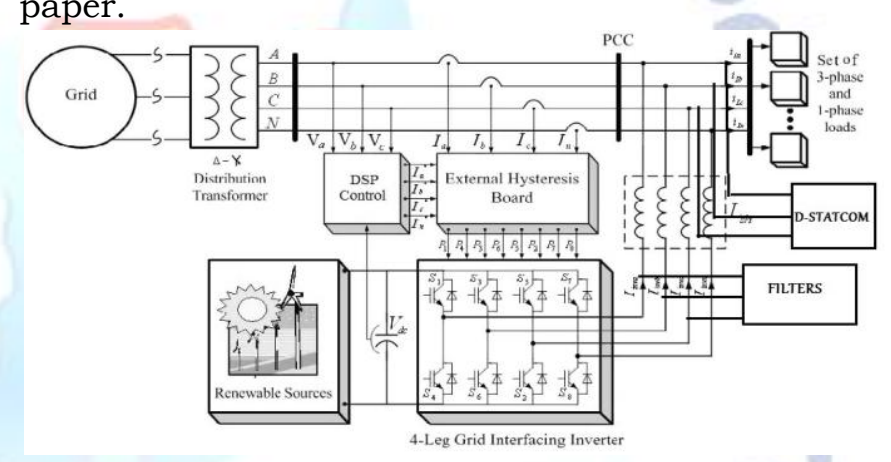

Fig. 1 Schematic of proposed renewable based distributed generation system

\section{Description OF THE SYSTEM}

\section{A. Topology}

An Active power filters are power electronic devices that cancel out unwanted harmonic currents by injecting a compensation current which cancels harmonics in the line current. Shunt active power filters compensate load current harmonics by injecting equal-but opposite harmonic compensating current. Generally, four-wire APFs have been conceived using four leg converters [5]. This topology has proved better controllability [6] than the classical three-leg four-wire .In this paper, it is shown that using an adequate control strategy, even with a three phase four-wire system, The topology of the investigated $\mathrm{APF}$ and its interconnection with the grid is presented in Fig. 1. It consists of a three-leg four-wire voltage source inverter. In this type of 
applications, the VSI operates as a current controlled voltage source. The proposed system is Three Phase Four wire which consists of wind turbine system connected to the dc-link of a grid interfacing inverter as shown in Fig. 1. The voltage source inverter is a key element of a wind system as it interfaces the renewable energy source to the grid and delivers the generated power. The Wind Turbine system is connected to grid with an inverter coupled to dc-link. The dc-capacitor decouples the Wind Turbine system from grid and also allows independent control of converters on either side of dc-link.

\section{B. Wind Turbine}

Wind turbines are used to convert the wind power into electric power. Electric generator inside the turbine converts the mechanical power into the electric power. Wind turbine systems are available ranging from $50 \mathrm{~W}$ to $2-3 \mathrm{MW}$. The energy production by wind turbines depends on the wind velocity acting on the turbine. Wind power is used to feed both energy production and consumption demand, and transmission lines in the rural areas.

Wind turbines can be classified with respect to the physical features (dimensions, axes, number of blade), generated power and so on. For example, wind turbines with respect to axis structure: horizontal rotor plane located turbines, turbines with vertical or horizontal spinning directions with respect to the wind. Turbines with blade numbers: 3-blade, 2-blade and 1-blade turbines.

On the other hand, power production capacity based classification has four subclasses.

$>$ Small Power Systems

$>$ Moderate Power Systems

$>$ Big Power Systems

$>$ Megawatt Turbines

\section{Voltage Source Converter (VSC)}

. A Voltage Source Converter (VSC) is a power electronic device that connected in shunt or parallel to the system. It can generate a sinusoidal voltage with any required magnitude, frequency and phase angle. It also converts the DC voltage across storage devices into a set of three phase AC output voltages. It is also capable to generate or absorbs reactive power. If the output voltage of the VSC is greater than AC bus terminal voltages, is said to be in capacitive mode. So, it will compensate the reactive power through AC system. The type of power switch used is an IGBT in anti-parallel with a diode. The three phase four leg VSI is modelled in Simulink by using IGBT.

\section{Controller for Active Power Filter}

The dc link voltage, Vdc is sensed at a regular interval and is compared with its reference counterpart $\mathrm{Vdc}^{*}$. The error signal is processed in a PI-controller. The output of the pi controller is denoted as Im. The reference current templates $\left(\mathrm{Ia}^{*}, \mathrm{Ib}^{*}\right.$, and $\left.\mathrm{Ic}^{*}\right)$ are obtained by multiplying this peak value $(\mathrm{Im})$ by the three-unit sine vectors ( $\mathrm{Ua}$, $\mathrm{Ub}$ and $\mathrm{Uc}$ ) in phase with the three source voltages. These unit sine vectors are obtained from the three sensed line to neutral voltages. The reference grid neutral current $\left(\mathrm{In}^{*}\right)$ is set to zero, being the instantaneous sum of balanced grid currents. Multiplication of magnitude Im with phases (Ua ,Ub, and Uc) results in the three phase reference supply currents $\left(\mathrm{Ia}^{*}, \mathrm{Ib}^{*}\right.$, and $\left.\mathrm{Ic}^{*}\right)$.

The grid synchronizing angle $(\Theta)$ obtained from phase locked loop (PLL) is used to generate unity vector template as

$$
\begin{aligned}
& U_{a}=\operatorname{Sin}(\theta) \\
& U_{b}=\operatorname{Sin}\left(\theta-\frac{2 \pi}{3}\right) \\
& U_{c}=\operatorname{Sin}\left(\theta+\frac{2 \pi}{3}\right) .
\end{aligned}
$$

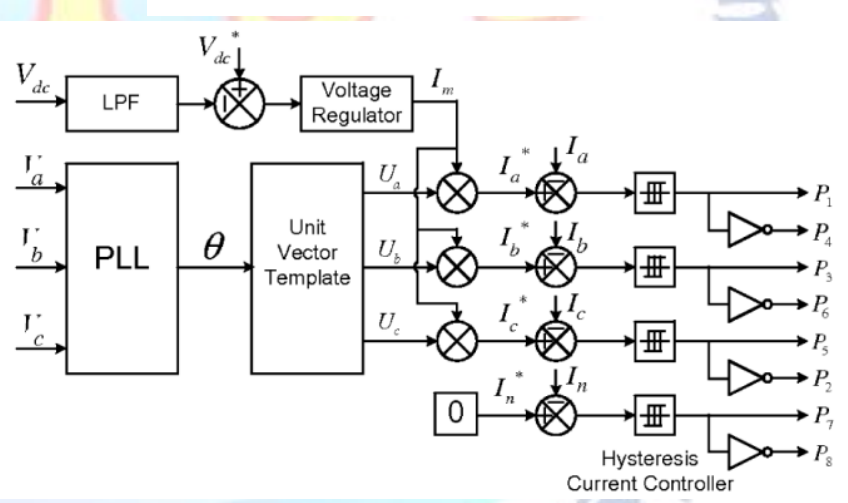

Fig.2. Control Scheme

The instantaneous values of reference three phase grid currents are compute as

$$
\begin{aligned}
& I_{a}^{*}=I_{m} \cdot U_{a} \\
& I_{b}^{*}=I_{m} \cdot U_{b} \\
& I_{c}^{*}=I_{m} \cdot U_{c} .
\end{aligned}
$$

The neutral current is considered as

$$
\mathrm{I}_{\mathrm{n}}{ }^{*}=0
$$

The reference grid currents(Ia*, Ib*, Ic*and In*) are compared with actual grid currents(Ia, Ib,Icand In) to compute the current errors as 


$$
\begin{aligned}
& I_{\text {aerr }}=I_{a}^{*}-I_{a} \\
& I_{\text {berr }}=I_{b}^{*}-I_{b} \\
& I_{\text {cerr }}=I_{c}^{*}-I_{c} \\
& I_{\text {nerr }}=I_{n}^{*}-I_{n} .
\end{aligned}
$$

These error signals are given to hysteresis current controller then generates the switching pulses for six IGBTs of the grid interfacing inverter.

\section{E. D-STATCOM}

D-STATCOM is also capable to generate or absorbs reactive power. If the output voltage of the VSC is greater than AC bus terminal voltages, D-STATCOM is said to be in capacitive mode. So, it will compensate the reactive power through AC system and regulates missing voltages. These voltages are in phase and coupled with the AC system through the reactance of coupling transformers.

Suitable adjustment of the phase and magnitude of the DSTATCOM output voltages allows effectives control of active and reactive power exchanges between D-STATCOM and AC system. In addition, the converter is normally based on some kind of energy storage, which will supply the converter with a DC voltage.

\section{HySTERESIS CURRENT ContRol}

The hysteresis current control (HCC) is the easiest control method to implement; it was developed by Brod and Novotny in 1985 . The shunt APF is implemented with three phase current controlled VSI and is connected to the ac mains for compensating the current harmonics. The VSI gate control signals are brought out from hysteresis band current controller. A hysteresis current controller is implemented with a closed loop control system and waveforms are shown in Fig .3. An error signal is used to control the switches in a voltage source inverter. This error is the difference between the desired current and the current being injected by the inverter. If the error exceeds the upper limit of the hysteresis band, the upper switch of the inverter arm is turned off and the lower switch is turned on. As a result, the current starts decaying.

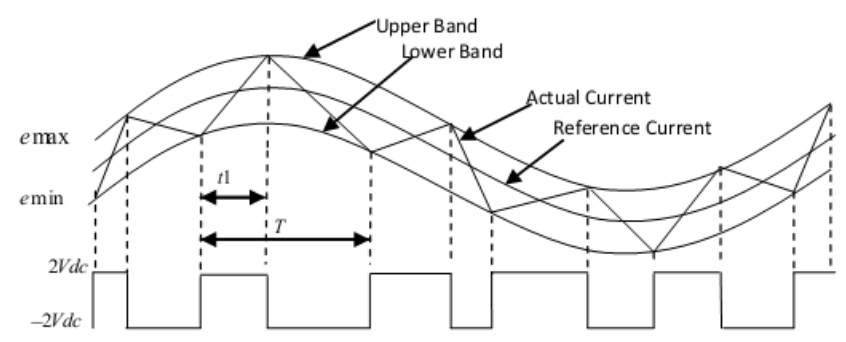

Fig. 3.Waveform of Hysteresis current controller

If the error crosses the lower limit of the hysteresis band, the lower switch of the inverter arm is turned off and the upper switch is turned on. As a result, the current gets back into the hysteresis band. The minimum and maximum values of the error signal are $\mathrm{e}_{\min }$ and $\mathrm{e}_{\max }$ respectively. The range of the error signal $e_{\max }-e_{\min }$ directly controls the amount of ripple in the output current from the VSI.

\section{Simulink Circuit}

The performance of the proposed structure is assessed by a computer simulation that uses MATLAB Software.

In order to verify the proposed control approach to achieve multi-objectives for grid interfaced DG systems connected to a 3-phase 4-wire network, an extensive simulation study is carried out using MATLAB/Simulink. A 4-leg current controlled voltage source inverter is actively controlled to achieve balanced sinusoidal grid currents at unity power factor (UPF) despite of highly unbalanced nonlinear load at PCC under varying renewable generating conditions. A RES with variable output power is connected on the dc-link of grid-interfacing inverter. An unbalanced 3-phase 4-wire nonlinear load, whose unbalance, harmonics, and reactive power need to be compensated, is connected on PCC. The waveforms of grid voltage $(V a, V b, V c)$, grid currents (Ia,Ib,Icand In ), unbalanced load current and inverter currents Ila,Ilb,Ilcand Iln are shown in Fig. 6. The corresponding active-reactive powers of grid (Pload,Qload), load and inverter(Pinv, Qinv)

Positive values of grid active-reactive powers and inverter active-reactive powers imply that these powers flow from grid side towards $\mathrm{PCC}$ and from inverter towards PCC, respectively. The active and reactive powers absorbed by the load are denoted by positive signs. Initially, the grid-interfacing inverter is not connected to the network (i.e., the load power demand is totally supplied by the grid alone). 


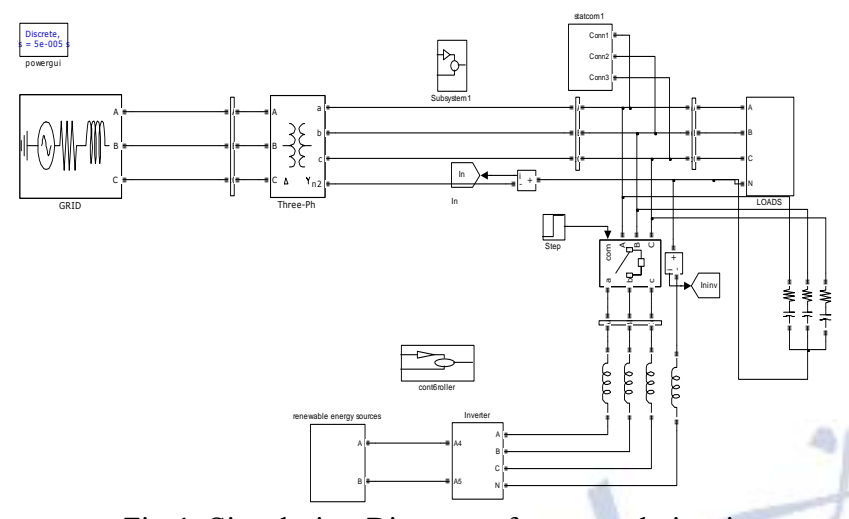

Fig 4: Simulation Diagram of proposed circuir

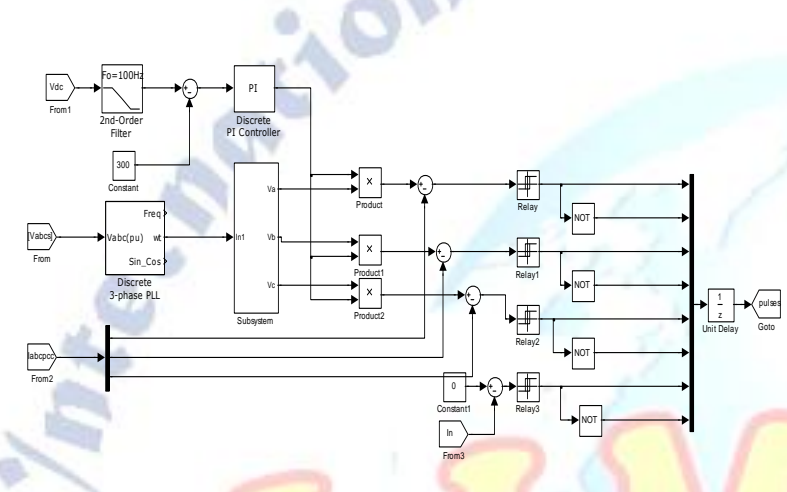

Fig 5: Simulation Diagram of Control circuit

V. Simulation Results

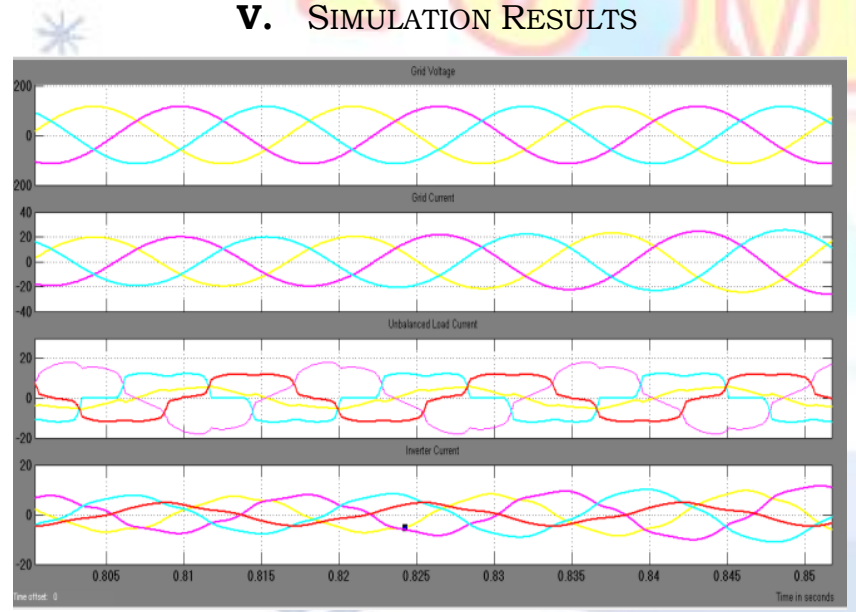

Fig 6: Simulation results: (a) Grid voltages, (b) Grid Currents (c) Unbalanced load currents, (d) Inverter Currents

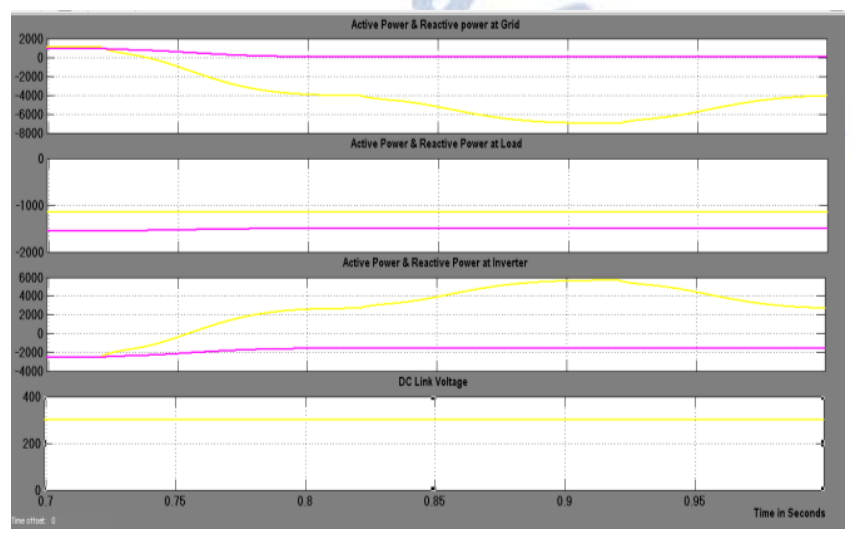

Fig 7:Simulation results: (a) PQ-Grid, (b) PQ-Load, (c) PQ-Inverter, (d) dc-link voltage

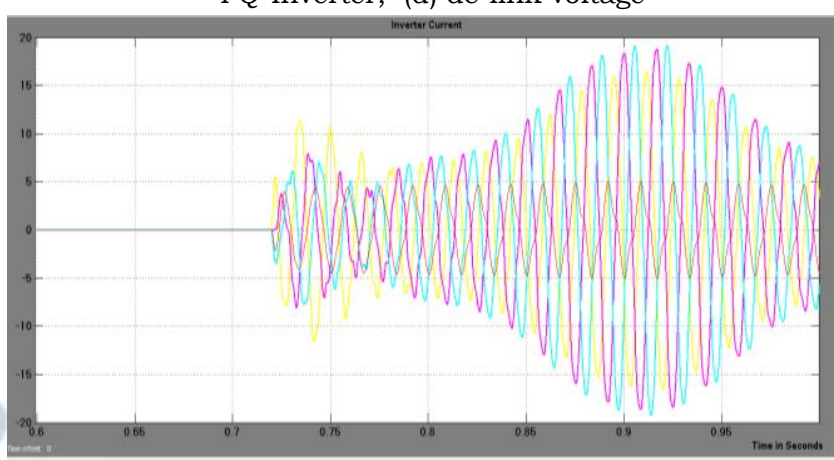

Fig 8: Inverter Current

Fig. 6 shows the source current, load current, inverter compensating current respectively. The inverter is turned on at 0.7 seconds. Fig. 6 (a) : it clearly indicates the source current from 0 to 0.7 sec represents the non-sinusoidal nature due to the presence of nonlinear load .At 0.7 seconds the nature of waveform is sinusoidal this represents the inverter compensated the non sinusoidal wave to balanced sinusoidal wave. The load current waveform is shown in Fig. 6 (c) .The inverter supplies the compensating current that is shown in Fig. 6 (d).

\section{TOTAL HaRmonic Distortion ANalysis OF INVERTER AT PCC}

The main criterion for assessing the quality of the voltage delivered by an inverter is the Total Harmonic Distortion (THD). This section will be devoted to analysing the inverters. The goal is to see the low order harmonics amplitude to be decreased. The inverter is usually followed by a low pass filter since higher frequency harmonics are easy to filter. Lower order harmonics generate the most important currents when an inductive load is used.

The THD is a ratio between the Root Mean Square (RMS) of the harmonics and the fundamental signal. For an inverter that has a fundamental output voltage V1 and harmonics V2, $\mathrm{V} 3, . . .$, we define the THD as follows:

$$
T H D=\frac{\sqrt{\sum_{k \geq 2}^{N} V_{k}^{2}}}{V_{1}}
$$

The THD of the circuit at the distribution level when the three-phase four leg inverter is used is $13 \%$. But the Total Harmonic Distortion is reduced to $8 \%$ when the LC filters are connected at the output of the inverter and the D-STATCOM at the Point of Common Coupling (PCC).

\section{CONCLUSIONS}


This paper has presented a novel control of an existing grid interfacing inverter to improve the quality of power at PCC for a 3-phase 4-wire DG system, filters and D-STATCOM. It has been shown that the grid-interfacing inverter can be effectively utilized for power conditioning without affecting its normal operation of real power transfer. The filters can mitigate the harmonics in the output of the inverter and the D-STATCOM can compensate the voltage at the distribution level. The grid-interfacing inverter with the proposed approach can be utilized to:

i) Inject real power generated from RES to the grid, and/or,

ii) Operate as a shunt Active Power Filter (APF).

This approach thus eliminates the need for additional power conditioning equipment to improve the quality of power at PCC. Extensive MATLAB/Simulink simulation as well as the DSP based experimental results have validated the proposed approach and have shown that the grid-interfacing inverter can be utilized as a multi-function device.

\section{REFERENCES}

[1] J. M. Guerrero, L. G. de Vicuna, J. Matas, M. Castilla, and J. Miret, "A wireless controller to enhance dynamic performance of parallel inverters in distributed generation systems," IEEE Trans. Power Electron., vol. 19, no. 5, pp. 1205-1213, Sep. 2004.

[2] J. H. R. Enslin and P. J. M. Heskes, "Harmonic interaction between a large number of distributed power inverters and the distribution network," IEEE Trans. Power Electron., vol. 19, no. 6, pp. 1586-1593, Nov. 2004.

[3] U. Borup, F. Blaabjerg, and P. N. Enjeti, "Sharing of nonlinear load in parallel-connected three-phase converters," IEEE Trans. Ind. Appl., vol. 37, no. 6, pp. 1817-1823, Nov./Dec. 2001.

[4] P. Jintakosonwit, H. Fujita, H. Akagi, and S. Ogasawara, "Implementation and performance of cooperative control of shunt active filters for harmonic damping throughout a power distribution system," IEEE Trans. Ind. Appl., vol. 39, no. 2, pp. 556-564, Mar./Apr. 2003.

[5] F. Blaabjerg, R. Teodorescu, M. Liserre, and A. V. Timbus, "Overview of control and grid synchronization for distributed power generation systems," IEEE Trans. Ind. Electron., vol. 53, no. 5, pp. 1398-1409, Oct. 2006.

[6] J. M. Carrasco, L. G. Franquelo, J. T. Bialasiewicz, E. Galván, R. C. P. Guisado, M. Á. M. Prats, J. I. León, and N. M. Alfonso, "Powerelectronic systems for the grid integration of renewable energy sources: A survey," IEEE Trans. Ind. Electron., vol. 53, no. 4, pp. 1002-1016, Aug. 2006. 